\title{
Study on the Morphology and Frequency of the Vomeronasal Organ in Humans
}

\author{
Estudio sobre la Morfología y la Frecuencia del Órgano Vomeronasal en los Seres Humanos
}

"Maria de Fátima Pereira de Carvalho, ${ }^{* *}$ Adriana Leal Alves \& ${ }^{* * *}$ Mirna Duarte Barros

CARVALHO, M. F. P.; ALVES, A. L. \& BARROS, M. D. Study on the morphology and frequency of the vomeronasal organ in humans. Int. J. Morphol., 26(2):283-288, 2008.

SUMMARY: The vomeronasal organ was first described in humans in the seventeenth century. It has a chemosensory function and is found in the mucosa of the nasal septum of mammals and consists of an opening in the mucosa at the base of the nasal septum. For this study, 143 individuals undergoing nasofibrolaryngoscopy were studied, and presence of the vomeronasal organ was considered to be a finding from the examination. Three morphological types of vomeronasal organ were observed: fissure, fossette and circular. The total prevalence of the vomeronasal organ among these patients was 28\% (40 individuals). The prevalence of the vomeronasal organ in this study population is compatible with what has been reported in other studies. The forms of the vomeronasal organ can be characterized: fissure, fossette and circular. The fossette type is commonest in males and the fissure among females.

KEY WORDS: Vomeronasal organ; Human; Anatomy.

\section{INTRODUCTION}

The vomeronasal organ (VNO) opens up in the mucosa at the base of the nasal septum. It has a variable shape in primates and is common and well developed as a chemosensory organ in other mammals (Monti-Bloch et al., 1998). In humans, the discovery of the VNO is attributed to the Dutch anatomist and surgeon Frederick Ruysch, in 1703, who described a small organ in the nose of a two-year-old child (Abolmaali et al., 2000). Ruysch presented only the right lateral view of the nasal septum in an illustration, but did not name this organ (Abolmaali et al.; Bhatnagar \& Smith, 2003).

The VNO was subsequently named by Ludwig Levin Jacobson, who described it in non-human mammals. For this reason, it is also called Jacobson's organ (Abolmaali et al.; Bhatnagar \& Smith). Kolliker was the first to provide evidence for the presence of the VNO in humans, and he was able to identify it histologically both in embryos and in adults (Abolmaali et al.; Bhatnagar \& Smith). The human VNO consists of a small pouch of approximately $2 \mathrm{~mm}$ in depth, located $1 \mathrm{~cm}$ from the nostrils. It opens as small orifice on each side of the mucosa that covers the nasal septum (Monti-Bloch et al.) (Fig. 1). In the literature, the frequency of the VNO in humans ranges from 25 to $90 \%$ (Abolmaali et al.). This wide variation is related to the investigation method and the difficulty of detecting the opening of the VNO on the surface of the nasal mucosa (Zbar et al., 2000).

Differences in the shape and size of the opening of the VNO have been described. Zbar et al. described three types according to the size of the orifice present in the mucosa of the nasal septum, while Besli et al. (2004) reported three types based on the shape of the opening: oval, fissure or elliptical .

The VNO is covered with simple or pseudo-stratified columnar epithelium, supported on a specific lamina that is rich in blood capillaries (Knecht et al., 2001). Some authors have indicated the presence of cells similar to bipolar neurons, between the epithelial cells (Monti-Bloch et al.; Meredith, 2001). According to Meredith, the human VNO contains cells similar to sensory neurons, but did not identify

\footnotetext{
MD, Instructor Professor Department of Morphology, Faculdade de Ciências Médicas da Santa Casa de São Paulo (SP), Brazil.

** MD. PhD. Instructor Professor Department of Morphology, Faculdade de Ciências Médicas da Santa Casa de São Paulo (SP), Brazil.
}

*** BSc, PhD. Adjunct Professor Department of Morphology, Faculdade de Ciências Médicas da Santa Casa de São Paulo (SP), Brazil. 
any axons. On the other hand, Monti-Bloch et al. demonstrated depolarization in the epithelium of the VNO, during local stimulation using substances secreted by the human skin.

The VNO develops from the medial wall of the nasal placode and grows during gestation. During the final phase of fetal life, it is believed that the VNO starts to regress and generally disappears, together with its nerves and accessory bulbs. The vomeronasal cartilage is usually the only remaining adult manifestation of these vestigial organs, and is located between the lower margin of the cartilage of the nasal septum and the vomer (Moore \& Persaud, 2004). In a recent study, it was demonstrated that the VNO in human fetuses at birth was larger in $70 \%$ of the individuals studied than was the VNO measured in the tenth week of gestation. This was also observed in $85 \%$ of VNOs in adults, thus indicating that this organ does not atrophy or degenerate during fetal life but, rather, develops into a mature organ (Monti-Bloch et al.).

Mammals respond to volatile substances through two different olfactory systems: the Main Olfactory System (MOS) and the Accessory Olfactory System (AOS). The MOS and AOS cannot be completely separated in functional terms (Meredith, 1991). The MOS is important as a molecular receptor for substances from the environment that are fundamental in the smell recognition stage. Moreover, it triggers the appropriate responses for each situation encountered, by mediating learned tasks (Meredith, 1991).

In animals, the AOS is formed by chemoreceptor neurons in the VNO and is connected with the accessory olfactory bulb, amygdala and part of the frontal lobe of the brain (Meredith). In humans, there is no accessory olfactory bulb. There are descriptions of nerve endings that go out from the VNO to the mucosa of the nasal septum and go in an intracranial direction, medially and parallel to the olfactory tract, but there is no anatomical or functional proof of a connection with the central nervous system. Some studies have demonstrated a positive chemosensory response from epithelial cells of the human VNO (MontiBloch et al.; Knecht et al.).

Pheromones are odorless and invisible chemical substances that modulate communication between individuals of the same species. They are substances secreted by one individual to the environment and received by another individual of the same species, thereby triggering a specific reaction. In humans, there is evidence that some substances act as pheromones of primer type, by triggering a series of physiological, neuroendocrine or behavioral events. The best known so far relate to the menstrual synchronization between women who lived together for a few months (Dalacqua \& Barros, 2006). Human pheromones or substances that can be perceived by the human VNO are called vomeropherins and activate areas of the central nervous system such, as the hypothalamus, amygdala and prefrontal cortex (Monti-Bloch et al.). Berglund et al. (2006) studied cerebral activation and, particularly, hypothalamic activation following inhalation of two human pheromones. They suggested that human pheromones may be processed bimodally: as smells (via the MOS) and as pheromones.

The aims of the present study were to investigate the frequency of occurrence of the VNO in humans, describe the morphological types and analyze their frequencies in the study population.

\section{MATERIAL AND METHOD}

This study was of mixed observational type (caseseries and cross-sectional studies) with data collection carried out retrospectively. There were 143 individuals in this study, of whom 83 were female and 60 were male. Their ages ranged from 2 to 83 years (median of 32 years).

All these individuals underwent nasofibrolaryngoscopy using a flexible fiberscope (Machida ENT30PIII), light source (Ferrari), video camera (Toshiba CE IKN43H34) and video monitor (Panasonic). These individuals presented a variety of indications for undergoing the examination. Observations were made on these examinations from the recordings on VHS tape.

To avoid bias caused by variability between observers, the nasofibrolaryngoscopy examinations were analyzed by a single person. The presence of any symptoms in the area of the nasal septum or a history of any surgical procedure on the nose prior to the fiberscope examination were used as exclusion criteria for the sample analyzed in this study. The presence of an opening in the mucosa of the anterior region of the nasal septum, posteriorly to the limen nasi, was identified as a positive characteristic for the VNO.

The data were analyzed by means of the qui square and Student $t$ tests, with the aid of the SPSS 9.0 for Windows software (SPSS Inc., Chicago IL). Because this study involved collecting retrospective data, there was no need to draw up a subsequent informed consent statement. Because these archives were from a private clinic, the study was not submitted for approval by the Research Ethics Committee. 


\section{RESULTS}

Among the individuals studied $(\mathrm{n}=143)$, the frequency of the VNO was $28 \%$ (Table I).

Table I. Frequency of VNO among the individuals studied.

\begin{tabular}{lcc}
\hline & Frequency & $\%$ \\
\hline Absent & 103 & 72.0 \\
Present & 40 & 28.0 \\
Total & 143 & 100.0 \\
\hline
\end{tabular}

The VNO was present in $27.7 \%$ of the females and $28.3 \%$ of the males (Table II). No relationship was observed between the presence of the VNO and sex $(\mathrm{p}=0.935)$.

Table II. Percentage occurrences of the VNO among females and males.

\begin{tabular}{lccccr}
\hline & & & \multicolumn{2}{c}{ Vomeronasal organ } & Total \\
& & & Absent & Present & \\
\hline Sex & Female & $\mathrm{n}$ & 60 & 23 & 83 \\
& & $\%$ Sex & 72.3 & 27.7 & 100 \\
& \multirow{4}{*}{ Male } & $\mathrm{n}$ & 43 & 17 & 60 \\
& & $\%$ Sex & 71.7 & 28.3 & 100 \\
& & $\mathrm{n}$ & 103 & 40 & 143 \\
& & $\%$ Sex & 72 & 28 & 100 \\
\hline
\end{tabular}

Only one individual (of male sex) presented bilateral VNOs. All the other 39 individuals presented a unilateral VNO, among whom $40 \%$ had it on the right side $(\mathrm{n}=16)$ and $57.5 \%$ had it on the left side $(n=23)$ (Table III).

Table III. Percentage occurrence of the VNO on the right and left sides of the nasal septum.

\begin{tabular}{lcr}
\hline & Frequency & \multicolumn{1}{c}{$\%$} \\
\hline Right & 16 & 40.0 \\
Left & 23 & 57.5 \\
Bilateral & 1 & 2.5 \\
Total & 40 & 100.0 \\
\hline
\end{tabular}

Three types of VNO were identified, which differed with regard to their opening in the nasal mucosa and were named as demostrated in figures 1, 2 and 3 .

The most frequent morphological type was the fossette type (35\%). The circular and fissure types occurred at the same frequency: $32.5 \%$ each (Table IV). There was no association between VNO type and the side of occurrence $(\mathrm{p}=0.273)$.

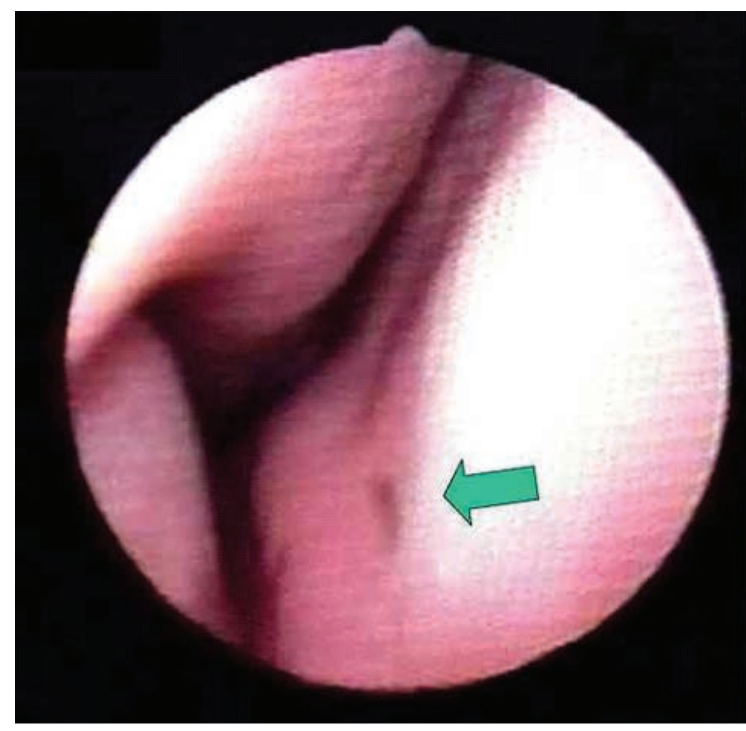

Fig. 1. VNO of fissure type on the right side of the nasal septum. Fissure narrow opening with greater length than width.

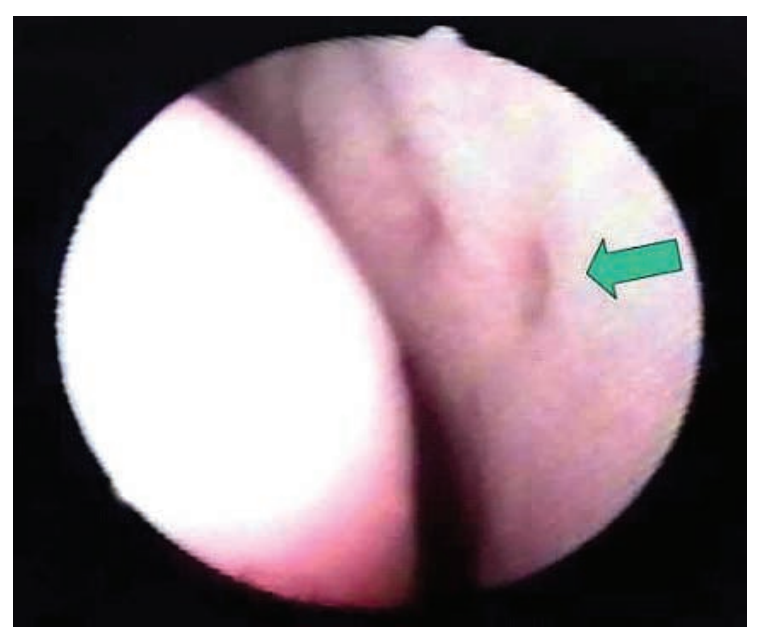

Fig. 2. VNO of circular type on the right side of the nasal septum. Circular opening with slightly raised edges .

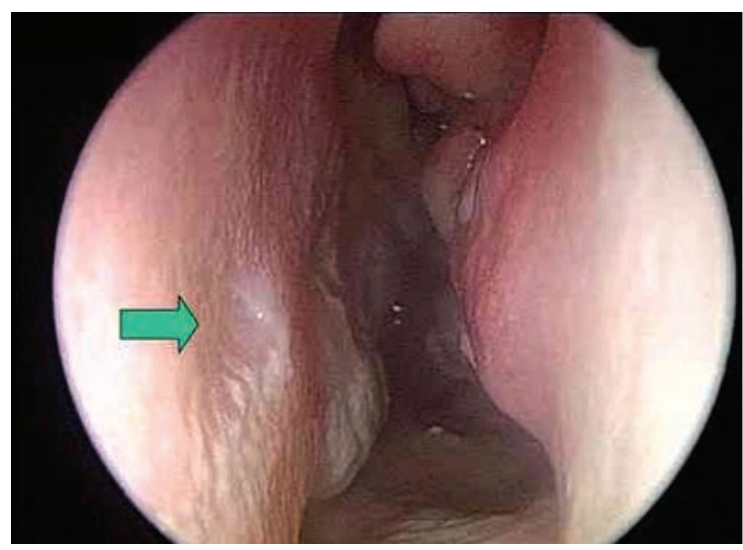

Fig. 3. VNO of fossette type on the left side of the nasal septum. Fossette opening delimiting a shallow depression in the mucosa with regular edges that were not raised. 
Table IV. Frequencies of different types of VNO.

\begin{tabular}{lcc}
\hline & Frequency & $\%$ \\
\hline Fossette & 14 & 35.0 \\
Circular & 13 & 32.5 \\
Fissure & 13 & 32.5 \\
Total & 40 & 100.0 \\
\hline
\end{tabular}

There was an association between morphological type and sex $(\mathrm{p}=0.012)$. Among the females, the most frequent type was the fissure type $(47.8 \%)$, while among the males it was the fossette type $(58.8 \%)$ (Table V).

Table V. Percentage occurrence of different types of VNO among males and females.

\begin{tabular}{|c|c|c|c|c|c|c|}
\hline & & \multicolumn{4}{|c|}{ Morphological pattern } & \multirow[t]{2}{*}{ Tota } \\
\hline & & & Fossette & Circular & Fissure & \\
\hline \multirow[t]{4}{*}{ Sex } & Female & $\mathrm{n}$ & 4 & 8 & 11 & 23 \\
\hline & & $\% \operatorname{Sex}$ & 17.4 & 34.8 & 47.8 & 100 \\
\hline & Male & $\mathrm{n}$ & 10 & 5 & 2 & 17 \\
\hline & & $\% \operatorname{Sex}$ & 58.8 & 29.4 & 11.8 & 100 \\
\hline \multirow[t]{2}{*}{ Total } & & $\mathrm{n}$ & 14 & 13 & 13 & 40 \\
\hline & & $\% \operatorname{Sex}$ & 35.0 & 32.5 & 32.5 & 100 \\
\hline
\end{tabular}

\section{DISCUSSION}

The frequency of the presence of the VNO opening found in this study $(28 \%)$ is within the range described in previous studies (Monti-Bloch et al.; Abolmaali et al.; Zbar et al.; Besli et al.). Other studies have described the complete anatomy of the VNO by imaging or histological analysis, in relation to both its opening in the nasal mucosa and the shape of the whole organ (Abolmaali et al.; Zbar et al.). In the present study, the presence of an opening in the mucosa of the nasal septum was considered to indicate the presence of the VNO in each individual studied.

The great variation in the frequency of the VNO in different studies is thought to be related to the accuracy of the evaluation method (anterior rhinoscopy versus nasofibrolaryngoscopy) and to the frequent presence of irregularities in the mucosa of this region, which would mask the diagnosis of the presence of VNO (Zbar et al.). In conformity with the results in the literature (Zbar et al.; Besli et al.), no relationship was observed between the presence of the VNO and sex.

The literature indicates that bilateral VNO is infrequent (Besli et al.; Meredith, 2001). In the population of the present study, only one individual presented bilateral VNO. Thus, statistical analysis of this finding and comparison with what is described in the literature was not possible. The VNO opens through an orifice in the mucosa of the nasal septum that can be viewed and classified with regard to its shape. Besli et al. recognized three types of
VNO: oval, elliptical and fissure, although they did not describe the morphological characteristics for identifying each of these (Besli et al.).

Winter et al. (2003) studied the VNO by means of magnetic resonance and identified two anatomical types for the VNO: tubular and saclike. The tubular type was more frequent and there was a significant relationship between VNO length and sex, such that the VNO was longer among males (Dalacqua \& Barros). In the present study, the frequencies of VNO of fossette type among males and fissure type among females were found to be statistically significant, thus indicating differences in anatomical pattern between the sexes. Despite the statistically significant difference in morphological pattern of the VNO between females and males in this study, there is no data that could relate anatomical and functional differences between the sexes.

Savic et al. (2005) demonstrated that there was a difference in cerebral activation between men and women, following inhalation of human pheromones. These authors used a testosterone derivative, 4,16-androstadien-3-one (AND), which is found in sweat in concentrations ten times greater among men than among women, and a steroid similar to estrogen, estra-1,3,5(10),16-tetraen-3-ol (EST), which is found in the urine of pregnant women. These authors considered these substances to be human pheromones. In positron-emitting tomography (PET) studies to analyze the cerebral blood flow following EST and AND inhalation, they 
demonstrated that different regions of the hypothalamus became activated in men and women. In women, AND activated the pre-optic area and ventromedial nuclei, while in men EST activated the paraventricular and dorsomedial nuclei. However, after inhalation of AND by men and EST by women, activation was observed in the amygdala, piriform cortex and anterior insular cortex (the olfactory regions of the MOS route). The difference in frequency of morphological patterns of the $\mathrm{VNO}$ between the sexes may be another of the factors leading to variation in pheromone perception between men and women.

There are indications that the VNO participates in AOS in humans. Recent studies have demonstrated cellular receptors in the epithelium of the VNO for substances called vomeropherins, which cause depolarization in these cells (Monti-Bloch et al.).

For otorhinolaryngologists, the VNO is generally considered to be an examination finding. It is often injured or removed during septoplasty, while performing subperichondrial detachment. If the VNO is considered to be a functional organ, the nonspecific alterations in olfactory pattern reported by some patients, who have undergone septoplasty may be related to injury to the VNO. New studies may elucidate whether the different morphological patterns of the VNO have any relationship with functional characteristics.

CARVALHO, M. F. P.; ALVES, A. L. \& BARROS, M. D. Estudio sobre la morfología y la frecuencia del órgano vomeronasal en los seres humanos. Int. J. Morphol., 26(2):283-288, 2008.

RESUMEN: El órgano vomeronasal se describió por primera vez en seres humanos en el siglo XVII. Tiene una función quimiosensorial y se encuentra en la mucosa del tabique nasal de los mamíferos. y consta de una abertura en la mucosa en la base del tabique nasal. Para este estudio, 143 individuos fueron estudiados mediante nasofibrolaringoscopía, y la presencia del órgano vomeronasal se consideró un hallazgo del examen. Tres tipos morfológicos de órgano vomeronasal se observaron: fisura, foseta y circular, siendo el tipo foseta es más común en los hombres y las fisuras entre las mujeres. La prevalencia total del órgano vomeronasal entre estos pacientes fue de $28 \%$ (40 pacientes). La prevalencia del órgano vomeronasal de la población en estudio es compatible con lo que ha sido reportado en otros estudios.

\section{PALABRAS CLAVE: Órgano vomeronasal; Hombre; Anatomía.}

\section{REFERENCES}

Abolmaali, N. D.; Kühnau, D.; Knecht, M.; Köhler, K.; Hüttenbrink, K. B. \& Hummel, T. Imaging of the Human Vomeronasal Duct. Chem. Senses, 26(1):35-9, 2000.

Besli, R.; Saylam, C.; Veral, A.; Karli, B. \& Ozek, C. The existence of the vomeronasal organ in human beings. $J$. Craniofac. Surg., 15(5):730-5, 2004.

Berglund, H.; Lindström, P. \& Savic, I. Brain response to putative pheromones in lesbian women. Proc. Natl. Acad. Sci. 103(21):8269-74, 2006.

Bhatnagar, K. P. \& Smith, T. D. The human vomeronasal organ. V. An interpretation of its discovery by Ruysch, Jacobson, or Kölliker, with an English translation of Kölliker (1877). Anat. Rec. B New. Anat., 270(1):4-15, 2003.

Dalacqua, M. \& Barros, M. D. Feromônios humanos. Arq. Méd. Hosp. Fac. Cienc. Méd. Santa Casa São Paulo, 51(1):27-31, 2006.

Knecht, M.; Kühnau, D.; Hüttenbrink, K. B.; Witt, M. \&
Hummel, T.Frequency and localization of the putative vomeronasal organ in humans in relation to age and gender. Laryngoscope, 111:448-52, 2001.

Meredith, M. Human vomeronasal organ function: a critical review of best and worst cases. Chem. Senses, 26(4):433$45,2001$.

Meredith, M. Sensory processing in the main and accessory olfactory systems: comparisons and contrasts. J. Steroid Biochem. Mol. Biol., 39(4B):601-14, 1991.

Monti-Bloch, L.; Jennings-White, C. \& Berliner, D. L. The Human Vomeronasal System. A Review. Ann. N. Y. Acad. Sci., 855:373-89, 1998.

Moore, K. L. \& Persaud, T. V. N. Aparelho Faríngeo. In: Moore, K. L. \& Persaud, T. V. N. (eds). Embriologia Clínica. $7^{\mathrm{a}}$ ed. Rio de Janeiro, Elsevier, 2004. pp. 253-5.

Savic, I.; Berglund, H. \& Lindström, P. Brain response to putative pheromones in homosexual men. Plast. Reconstr. Surg., 102(20):7356-61, 2005. 
Winter, D.; Abolmaali, N. D.; Knecht, M. \& Hummel, T. The endoscopically and radiological visualization of the human vomeronasal organ. Otolaryngol. Head Neck Surg., 129(2):147-8, 2003.

Zbar, R. I.; Zbar, L. I.; Dudley, C.; Trott, S. A.; Rohrich, R. J. \& Moss, R. L. A classification schema for the vomeronasal organ in humans. Plast. Reconstr. Surg., 105(4):1284-8, 2000.
Correspondence to:

Prof. Maria de Fátima Pereira de Carvalho

Departamento de Morfologia

Faculdade de Ciências Médicas da Santa Casa de São Paulo

Rua Cesário Motta Júnior, 61

CEP 01221-020

São Paulo (SP) BRASIL

Tel/ Fax (5511) 2176-7000 ramal 5509

Email: fatimaorl@hotmail.com

Received: 16-10-2007

Accepted: 14-02-2008 